\title{
Analysis of the variations of follicular fluid composition during follicular growth and maturation in the mare using proton nuclear magnetic resonance $\left({ }^{1} \mathrm{H} N M R\right)$
}

\author{
N. Gérard ${ }^{1 *}$, S. Loiseau ${ }^{1}$, G. Duchamp ${ }^{1}$ and F. Seguin ${ }^{2 \dagger}$ \\ ${ }^{1}$ Equipe Reproduction Equine, PRC, INRA-Haras Nationaux, F-37380 Nouzilly, France; and \\ ${ }^{2}$ Laboratoire de Résonance Magnétique Nucléaire, PPF Microscopie Electronique et RMN, \\ INSERM U316, Faculté de Médecine, F-37032 Tours, France
}

Follicular development and ovulatory processes in mammals involve local biochemical changes as a result of substantial modifications in cellular metabolism, the most well known of which is steroid variation. In the present study, the intrafollicular variation of several other components was studied using proton nuclear magnetic resonance ( ${ }^{1} \mathrm{H}$ NMR). This approach made it possible to demonstrate that the intrafollicular biochemical content changes during follicular growth and maturation. Follicular fluid was aspirated by ovarian puncture of the dominant follicle at various physiological stages of its development: early dominant, late dominant and preovulatory. Serum samples were collected during each puncture session. ${ }^{1} \mathrm{H}$ NMR was used to evaluate intrafollicular and circulating glycoconjugates (sugar chains and $\mathrm{N}$-acetyl groups), lipoproteins $\left(\mathrm{CH}_{3}\right.$ and $\mathrm{CH}_{2}$ groups), glucose metabolites (trimethylamines, acetate and lactate), amino acids (glutamine/glutamate and alanine), creatine/ creatinine and polyamines. Follicular fluids were assayed by radioimmunoassay for oestradiol and progesterone contents. The intrafollicular contents of alanine and lipoproteins $\left(\mathrm{CH}_{3}\right.$ groups) decreased in the dominant follicle during growth, whereas concentrations of progesterone and oestradiol increased significantly. After injection of gonadotrophin to induce ovulation, follicular maturation was characterized by a decrease in glycoconjugates (sugar chains), trimethylamines and acetate, a decrease in oestradiol concentration, and a further increase in $\mathrm{CH}_{3}$ groups of lipoproteins and progesterone. The results from the present study showed a clear correlation between the intrafollicular content of alanine and that of oestradiol. A correlation between progesterone and glycoconjugates (sugar chains) was also observed. Therefore, ${ }^{1} \mathrm{H}$ NMR was shown to be effective for studying specific changes in the biochemical composition of the follicular fluid that occur during follicular development. For the first time, the variation of several compounds (glycoconjugates, lipoproteins, glucose metabolites, amino acids and polyamines) in relation to growth and maturation was demonstrated. Some of these changes could be of crucial importance for follicular maturation and ovulation as well as for oocyte maturation and further fertilization.

\section{Introduction}

Typically, in the mare, one follicle is selected from the cohort of recruited follicles. This follicle continues to grow and becomes a dominant follicle whereas the remainder of the cohort undergo atresia. The dominant follicle produces a mature oocyte at ovulation.

Follicular fluid is the environment of the oocyte during its maturation in vivo. It is well known that follicular fluid is in part an exudate of serum, as surrounding cell layers permit

${ }^{*}$ Correspondence address: Reproduction Equine, UMR PRC 6073 INRA, F-37380 Nouzilly, France

†Present address: Laboratoire de Physique and Mathématiques, UFR Médecine and Pharmacie, 34 Rue du Jardin des Plantes, F-86005 Poitiers, France

Email: gerard@tours.inra.fr the free diffusion of proteins of up to $500 \mathrm{kDa}$ (Payer, 1975). This fluid is composed of locally produced substances which are related to the metabolic activity of ovarian cells. Moreover, various studies performed in several mammalian species demonstrate clearly that follicular fluid contains essential substances involved in oocyte maturation and fertilization. The fluid also contains molecules implicated in follicular cell proliferation and differentiation (for reviews, see Tsafriri, 1988; Adashi, 1994).

The chemical composition of fluid from the dominant follicles is important because it is an indicator of the secretory activities and metabolism of follicular cells and thus could be related to the follicular quality. It could also provide a useful indication of the requirements for cells, and oocyte growth and maturation. The composition may be used as a provisional guide for formulating cell culture conditions. 
This information could be of particular interest in equine species. Indeed, in the mare, the requirements for oocyte maturation in vitro appear to be unusual. The maturation rate of equine oocytes in vitro is $<60 \%$ in culture conditions adapted from those used in bovine species (Goudet et al., 1997, 1998; Hinrichs and Williams, 1997). Moreover, in vitro fertilization gives only limited success in this species (Palmer et al., 1991). Thus, oocyte maturation in the mare could involve some species-specific mechanisms, some of which may be related to essential factors contained in the equine follicular fluid. Nevertheless, a few soluble factors have been studied in the mare, the best known of which are steroids (Gérard and Monget, 1998; Gérard et al., 1998, 1999; Belin et al., 2000).

High resolution nuclear magnetic resonance (NMR) spectroscopy provides a unique tool for studying metabolites and metabolism in tissues. Initially, NMR spectroscopy was used mainly in biomedicine but it is found now in many physiological applications (for a review, see Van den Thrillart and Van Waarde, 1996). As the proton NMR $\left({ }^{1} \mathrm{H}\right.$ NMR) provides opportunities for obtaining qualitative and quantitative data from body fluids, it was hypothesized that this technique could provide information on equine follicular fluid and on intrafollicular changes that occur during follicular growth and ovulation. As some of these changes are probably of crucial importance for oocyte maturation and further fertilization, a better knowledge of the equine follicular fluid composition by ${ }^{1} \mathrm{H}$ NMR analysis should help to resolve some of the problems encountered during in vitro procedures in the mare.

In this context, the aim of the present study was to characterize equine follicular fluid and to explore the patterns of metabolites in follicular fluid and serum at the end of the follicular phase using ${ }^{1} \mathrm{H}$ NMR. The changes observed during follicular growth and maturation were related to the physiological status of the follicle, as assessed by steroid concentrations.

\section{Materials and Methods}

\section{Animals and experimental procedure}

Cyclic Welsh pony mares aged 3-19 years (INRA, Nouzilly) were used. All ponies were in good body condition, housed indoors, fed with concentrates and straw, and water was provided ad libitum. Mares were treated with $125 \mu \mathrm{g} \mathrm{PGF}_{2 \alpha}$ analogue (Cloprostenol, Estrumate; Pitman-Moore, Meaux) i.m. during the mid-luteal phase to induce luteolysis. Ovarian activity was then assessed by routine transrectal ultrasonic imaging (Aloka 210 with a $5 \mathrm{Mhz}$ linear probe, Tokyo), which allowed measurement of follicle diameter, and observation of follicular morphology and corpus luteum.

Follicular fluid was aspirated by a transvaginal ultrasoundguided follicular puncture using a 7.5 MHz sectorial probe (Kretz; Soframed, Truchtersheim) coupled to a sterile single lumen needle $(60 \mathrm{~cm}$ in length and $0.8 \mathrm{~mm}$ outer diameter;
Thiébaud Frères, Jouvernex Margencel), as described by Duchamp et al. (1995) and Okolski et al. (1995). A small amount of follicular fluid ( $<10 \%$ of total fluid volume) was aspirated from the dominant follicle twice during its growth. In a first group of mares, the dominant follicle was aspirated first at the early dominant stage ( 1 day after the largest follicle reached $20-22 \mathrm{~mm}$ in diameter) and then at the preovulatory stage (34 $\mathrm{h}$ after induction of ovulation by an i.v. injection of $25 \mathrm{mg}$ crude equine gonadotrophin (Duchamp et al., 1987) and from day 4 to day 6 after the early dominant puncture). In a second group of mares, the dominant follicle was aspirated first at the late dominant stage (1 day after the largest follicle reached 30-32 $\mathrm{mm}$ in diameter) and then at the preovulatory stage (34 h after induction of ovulation and 2 days after the late dominant stage puncture). All mares were inseminated on the day after the crude equine gonadotrophin injection $\left(200 \times 10^{6}\right.$ spermatozoa) (Magistrini et al., 1992) and pregnancy diagnosis was performed by ultrasonography 10-14 days after ovulation. During each ovarian puncture, blood samples were collected from the jugular vein for serum preparation. Follicular fluid and serum samples were then frozen immediately at $-20^{\circ} \mathrm{C}$ until analysis ( $<6$ months).

Before each ovarian puncture session, mares were sedated with a single i.v. injection of detomidine (Domosedan, $1 \mathrm{mg}(100 \mathrm{~kg})^{-1}$ body weight; Smithkline and French, Courbevoie). Prifinium bromide (Prifinial; Vetoquinol, Lure) was injected (45 mg (100 kg)-1 body weight, i.v.) to ensure rectal relaxation. After puncture sessions, mares were injected with an antibiotic (Mixtencilline, 1600000 iu penicillin $(100 \mathrm{~kg})^{-1}$ body weight and $1.3 \mathrm{~g}$ dihydrostreptomycine $(100 \mathrm{~kg})^{-1}$ body weight, i.m.; Rhône-Mérieux, Lyon).

\section{${ }^{1}$ H NMR analysis}

${ }^{1} \mathrm{H}$ NMR spectra were obtained with a 4.7 Tesla spectrometer AM 200 WB BRUKER (Wissenbourg) equipped with a $5 \mathrm{~mm}{ }^{1} \mathrm{H} /{ }^{13} \mathrm{C}$ probe with the sample spinning. Samples were prepared according to the optimized procedure described by Magistrini et al. (1995). In brief, frozen samples were thawed at $37^{\circ} \mathrm{C}$ and $400 \mu$ of this sample was added with $100 \mu \mathrm{l}$ of $5 \times 10^{-3}$ mol formic acid $\mathrm{I}^{-1}$ in deuterium water. Each sample was introduced in a $5 \mathrm{~mm}$ NMR tube and ${ }^{1} \mathrm{H}$ NMR signal was obtained at $200.13 \mathrm{MHz}$ with the following acquisition parameters: $2100 \mathrm{~Hz}$ of sweep width, a $8 \mathrm{~K}$ points memory location and a nonselective pulse of 90 and 128 accumulations with a $7 \mathrm{~s}$ repetition time. Water signal suppression was obtained by a $4 \mathrm{~s}$ selective pulse applied to water resonance before the non-selective pulse. Spectra were obtained after a Fourier transform performed in a $16 \mathrm{~K}$ points memory location.

For quantification of the compounds, formic acid was used as the internal standard (Kriat et al., 1992) and the peak area was determined by means of integrated software (DisNMR; Bruker) as described by Magistrini et al. (1995) and Seguin et al. (1995). The concentration of each 
compound was calculated using the method described by Kriat et al. (1992) and Magistrini et al. (2000). For identification of the compounds, some samples were prepared with trimethylsilylpropionic acid (TSP; $400 \mu \mathrm{l}$ of sample added with $100 \mu \mathrm{l} 5 \times 10^{-3} \mathrm{~mol} \mathrm{TSP} \mathrm{I}^{-1}$ in deuterium). Chemical shifts were determined with respect to the TSP standard and assignments were made either according to the published procedures or standard addition of reference compound.

\section{Hormone assays}

Concentrations of progesterone and oestradiol in follicular fluid were determined by radioimmunoassay without extraction, as described in horses (Gérard and Monget, 1998; Gérard et al., 1998; Belin et al., 2000). Intra-assay variability and limit of sensitivity were $8.1 \%$ and $0.10 \mathrm{ng} \mathrm{ml}^{-1}$ for progesterone and $6.3 \%$ and $0.015 \mathrm{ng} \mathrm{ml}^{-1}$ for oestradiol, respectively. For each steroid, all samples were analysed in the same assay to avoid interassay variability.

\section{Statistical analyses}

All data are presented as the mean \pm SEM. Comparisons of means between follicular fluid and matching serum as well as in follicular fluid between two successive punctures were made using the paired $t$ test. Comparisons of means between follicular fluid from different mares were analysed by group, using ANOVA followed by a Student's $t$ test. Correlations between variables were assessed by linear correlation analysis.

\section{Results}

\section{Follicular morphology and steroid concentrations}

Follicular size was chosen to programme the ovarian puncture procedure because of the high individual variability in the duration of oestrus. The first puncture of follicles was performed either at the early dominant stage or at the late dominant stage. A second aspiration of follicular fluid was performed at the preovulatory stage, $34 \mathrm{~h}$ after induction of ovulation. At this stage, punctured preovulatory follicles were considered healthy according to: (i) their diameter; (ii) their ultrasonic morphology (black, round area without echogenic dots); and (iii) the subsequent ovulation. Five mares in each experimental group had a growing dominant follicle with all of these parameters. The diameter of these follicles was $24 \pm 1 \mathrm{~mm}$ at the early dominant stage (4-6 days after prostaglandin injection, $n=5), 33.8 \pm 0.92 \mathrm{~mm}$ at the late dominant stage (612 days after prostaglandin injection, $n=5$ ) and $31.3 \pm$ $1.41 \mathrm{~mm}$ at the preovulatory stage (healthy preovulatory; $34 \mathrm{~h}$ after induction of ovulation, $n=10$ ). In each group, three of five mares showed a positive pregnancy diagnosis 10-14 days after insemination. Other punctured follicles were judged as unhealthy and atretic at the preovulatory stage on the basis of morphological ultrasonic abnormality (echogenic dots) and the absence of ovulation after induction by crude equine gonadotrophin injection. Such follicles had a smaller diameter $(27.8 \pm 3.02 \mathrm{~mm})$, which was not significantly different from the diameter of healthy preovulatory follicles. Blood contamination of follicular fluids was sometimes observed in these atretic preovulatory follicles during sampling, but was never observed in follicular fluid samples from healthy follicles.

Follicular concentrations of progesterone and oestradiol were determined to ascertain whether the punctured follicle was at the expected stage. The intrafollicular content of progesterone increased during follicular development between day 1 and day 2 of puncture for each group of mares: from early dominant $\left(63.4 \pm 19.3 \mathrm{ng} \mathrm{ml}^{-1}\right)$ to healthy preovulatory follicular fluid (1094.3 $\pm 170.9 \mathrm{ng}$ $\left.\mathrm{ml}^{-1}, \quad P<0.005\right)$, from late dominant $(105.8 \pm 43.1 \mathrm{ng}$ $\mathrm{ml}^{-1}$ ) to healthy preovulatory follicular fluid (1021.4 \pm $\left.170.1 \mathrm{ng} \mathrm{ml}^{-1}, P<0.005\right)$. The concentration of oestradiol was higher in late dominant than in early dominant follicular fluids $\left(2800.6 \pm 245.2 \mathrm{ng} \mathrm{ml}^{-1}\right.$ versus $1354.3 \pm$ $\left.138.8 \mathrm{ng} \mathrm{ml}^{-1}, P<0.001\right)$ and decreased between the late dominant and the healthy preovulatory follicular fluids $\left(2800.6 \pm 245.2 \mathrm{ng} \mathrm{ml}^{-1}\right.$ versus $1795.0 \pm 267.6 \mathrm{ng} \mathrm{ml}^{-1}$, $P=0.052)$.

\section{${ }^{1}$ H NMR spectra of follicular fluid and serum}

Spectra from 20 follicular fluids (five early dominant, five late dominant and ten healthy preovulatory follicles) and the 20 matching sera studied are shown (Fig. 1a,b, respectively). Given that follicular fluid and serum are complex biological fluids, numerous aliphatic structures were visualized. Sugar proton chains and $\mathrm{N}$-acetyl groups of glycoconjugates were seen at 3.3-4.0 and 2.0 p.p.m., respectively, $\mathrm{CH}_{3}$ and $\mathrm{CH}_{2}$ groups from lipoproteins between 0.6 and 1.4 p.p.m., trimethylamines at 3.2 p.p.m., acetate at 1.8 p.p.m., lactate at 1.4 and 4.1 p.p.m., amino acids glutamate/glutamine and alanine at 2.3 and 1.4 p.p.m., respectively, creatine/creatinine at 3.0 p.p.m. and polyamines at 1.7 and 2.6 p.p.m. Citrate was observed as a quadruplet peak at 2.6 p.p.m., which was not detected consistently. Moreover, the singlet peak at 3.1 p.p.m. and the doublet peak at 3.25 p.p.m. are not, to date, assigned to a known compound.

In serum, the doublet peak of lactate was not consistently well individualized, but was associated with the smeared peak of $\mathrm{CH}_{2}$ groups from lipoproteins (Fig. 1b).

\section{Comparison of serum and follicular fluid samples}

Quantitative measurements of circulating and intrafollicular concentrations of a number of compounds with well-resolved signals were obtained by reference to the concentration of formic acid, which was used as an internal quantitative standard. Eight peaks corresponding to chemical groups of sugar chains and $\mathrm{N}$-acetyl groups of glycoconjugates, $\mathrm{CH}_{3}$ groups of lipoproteins, trimethylamines, 


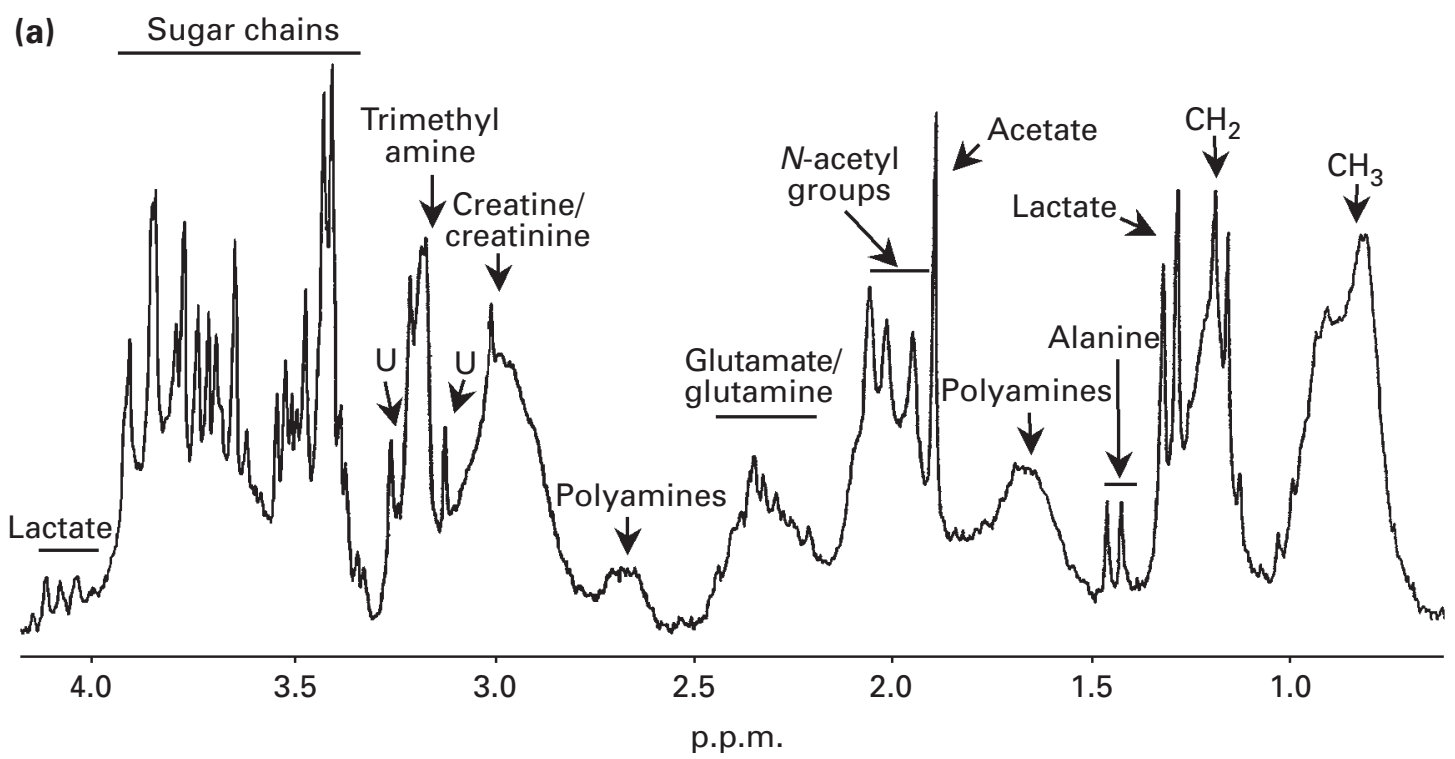

(b)
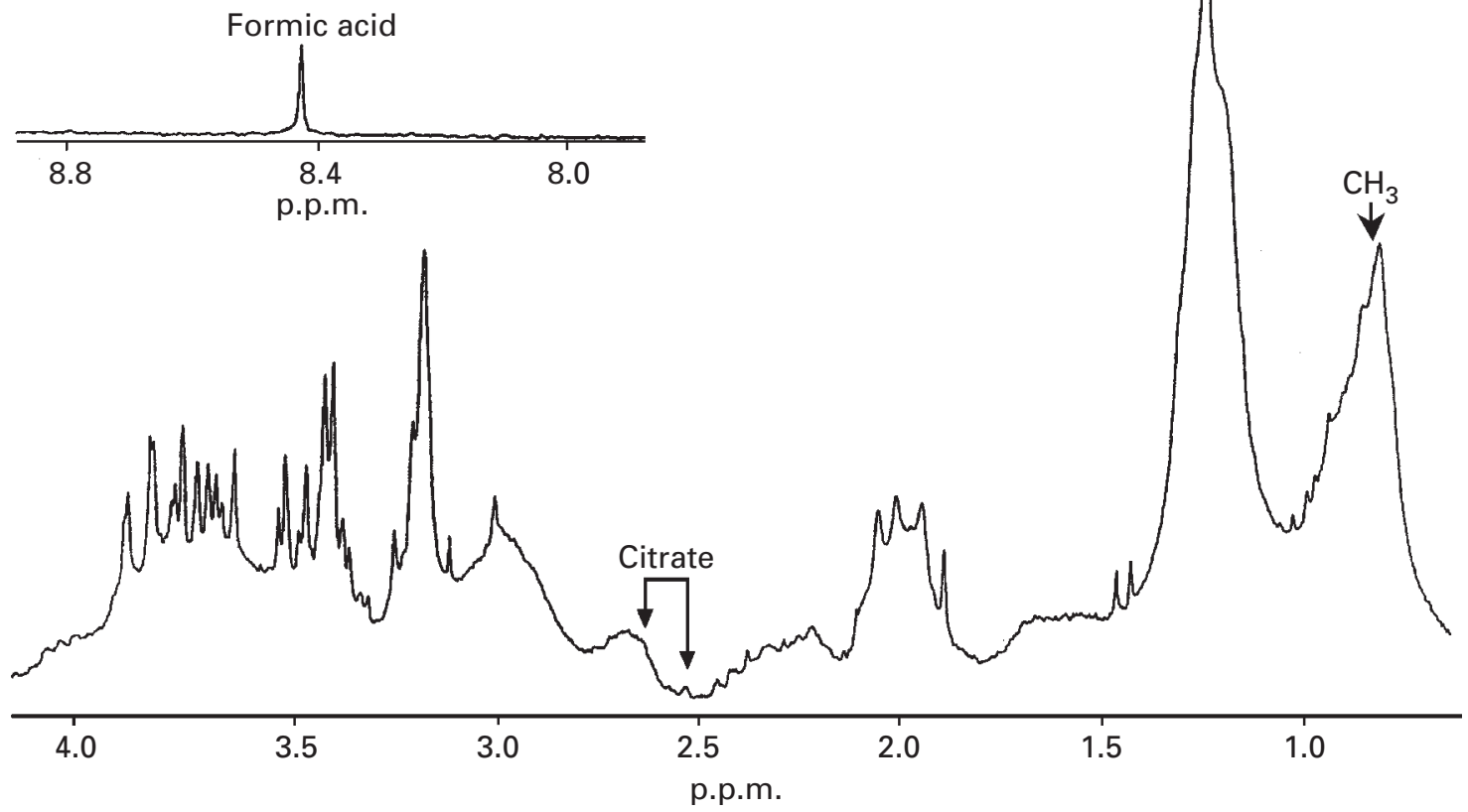

Fig. 1. Representative proton nuclear magnetic resonance $\left({ }^{1} \mathrm{H}\right.$ NMR) spectra of (a) equine follicular fluids $(n=20$ : five samples collected at the early dominant stage, five at the late dominant stage and ten at the preovulatory stage) and (b) matching sera $(n=20)$. Inset: spectral peak of formic acid used as quantitative internal reference. $\mathrm{U}$ : unassigned peaks.

acetate, alanine, creatine/creatinine and polyamines, plus the peak at 3.1 p.p.m. corresponding to an unidentified substance, were quantified (Fig. 2). Trimethylamine, $\mathrm{N}$-acetyl and methyl groups were present at significantly lower concentrations in follicular fluid than in serum $(P<0.001$,
$P<0.01$ and $P<0.001$, respectively), whereas acetate, polyamines and alanine were present at higher concentrations in follicular fluid than in serum $(P<0.01, P<0.05$ and $P<0.05$, respectively). Creatine, the unidentified product (3.1 p.p.m.) and sugar chains of glycoconjugates 


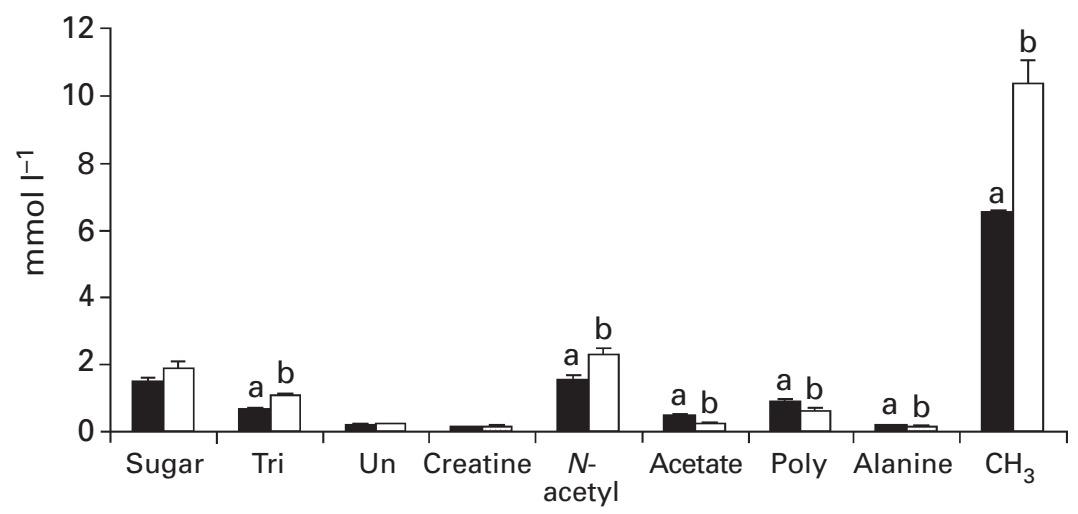

Fig. 2. Concentration of nine metabolites detected by proton nuclear magnetic resonance ( $\left.{ }^{1} \mathrm{H} \mathrm{NMR}\right)$ in equine follicular fluids $(\boldsymbol{\square}, n=20$ : five samples collected at the early dominant stage, five at the late dominant stage and ten at the preovulatory stage) and matching sera $(\square)$. abFor each metabolite, bars with different letters are significantly different $(P<0.05)$. Sugar: sugar chains; Tri: trimethylamines; Un: unidentified metabolite; $\mathrm{N}$-acetyl: $\mathrm{N}$-acetyl groups; Poly: polyamines; $\mathrm{CH}_{3}: \mathrm{CH}_{3}$ groups of lipoproteins.

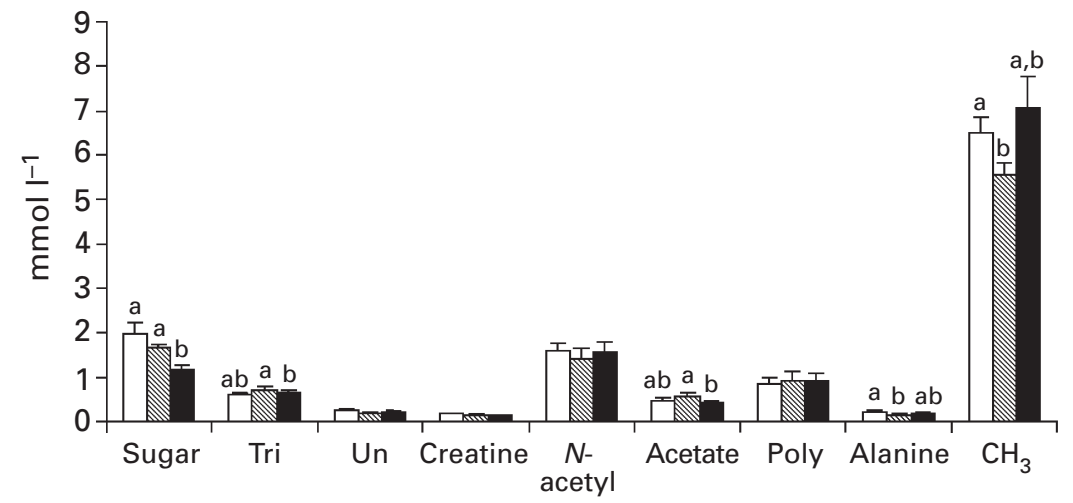

Fig. 3. Concentrations of nine metabolites detected by proton nuclear magnetic resonance $\left({ }^{1} \mathrm{H} \mathrm{NMR}\right)$ in equine follicular fluids aspirated from the dominant follicle at the early dominant $(\square, n=5)$, late dominant $(\mathbb{N}, n=5)$ and healthy preovulatory stages $(\mathbf{\square}, n=10)$. abFor each metabolite, bars with different letters are significantly different $(P<0.05$ at least). Sugar: sugar chains; Tri: trimethylamines; Un: unidentified metabolite; $\mathrm{N}$-acetyl: $\mathrm{N}$-acetyl groups; Poly: polyamines; $\mathrm{CH}_{3}: \mathrm{CH}_{3}$ groups of lipoproteins.

displayed no difference between the two biological fluids at any stage studied. At the preovulatory stage, the intrafollicular content of sugars was significantly lower than the circulating concentration of sugars $\left(1.15 \pm 0.13 \mathrm{mmol} \mathrm{I}^{-1}\right.$ versus $\left.1.96 \pm 0.36 \mathrm{mmol} \mathrm{I}^{-1}, P<0.05\right)$.

\section{Comparisons during follicular development}

Quantitative measurement of the eight peaks corresponding to sugar chains and $\mathrm{N}$-acetyl groups of glycoconjugates, $\mathrm{CH}_{3}$ groups of lipoproteins, trimethylamines, acetate, alanine, creatine/creatinine and polyamines, plus the peak at 3.1 p.p.m. corresponding to an unidentified substance, was performed in relation to the stage of the oestrous cycle. No significant difference was observed in sera between the various physiological stages studied (not shown). The results obtained with follicular fluids recovered at the three stages studied are shown (Fig. 3). Between early dominant and late dominant follicles, the intrafollicular contents of alanine and lipoproteins $\left(\mathrm{CH}_{3}\right.$ groups) decreased significantly (both $P<0.05$ ). The content of sugars tended to decrease between the early dominant and the late dominant stage $(P=0.06)$, and significantly decreased between the late dominant and the healthy preovulatory stage $(P<0.005)$. Similarly, trimethylamine and acetate contents were significantly lower at the healthy preovulatory than at the late dominant stage $(P<0.01$ and $P<0.05$, respectively). 


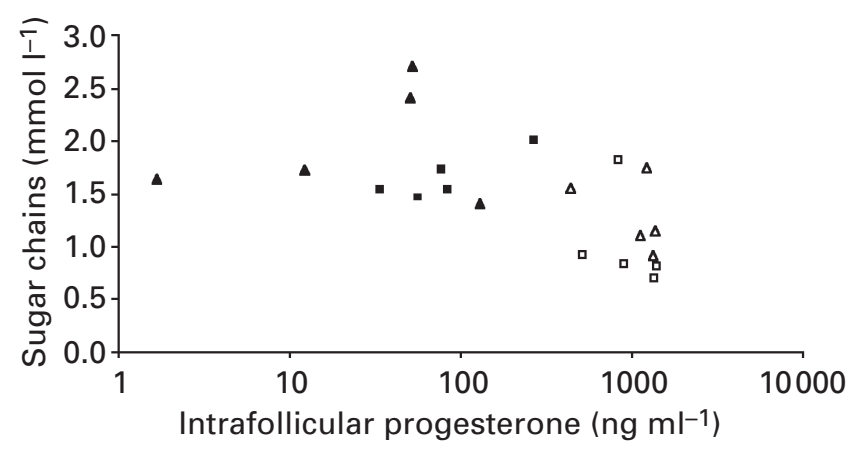

Fig. 4. Linear regression analysis of progesterone concentration in equine follicular fluid in relation to intrafollicular content of sugar chains from glycoconjugates, as measured by proton nuclear magnetic resonance $\left({ }^{1} \mathrm{H}\right.$ NMR $)(r=-0.646 ; P<0.01)$. ( $(\mathbf{\Delta})$ : Early dominant stage; $(\boldsymbol{\square})$ : healthy preovulatory stage after puncture at early dominant stage; $(\triangle)$ : late dominant stage; $(\square)$ : healthy preovulatory stage after puncture at late dominant stage.

\section{Statistical analyses}

Correlation analyses between intrafollicular and serum contents were performed to examine further the relationships between the two biological fluids. Concentrations of creatine, alanine, acetate and the unidentified product (3.1 p.p.m.) were positively correlated between follicular fluid and serum $(P<0.05, P<0.05, P<0.01$ and $P<0.01$, respectively; data not shown).

The relationship between follicular status and the different molecules analysed was examined further by relating intrafollicular contents to steroid concentrations. The intrafollicular content of alanine was correlated with oestradiol $(r=-0.486 ; P<0.05$, not shown). Moreover, it was noted that the amount of sugar chains of glycoproteins was negatively correlated with progesterone $(r=-0.646$, $P<0.01$, Fig. 4).

\section{Discussion}

The aim of the present study was to analyse the biochemical profiles of equine follicular fluid and serum in relation to the physiological and steroidogenic status of follicles. Accordingly, the high resolution technique ${ }^{1} \mathrm{H}$ NMR was used to visualize and quantify numerous molecules in serum and fluid from the dominant follicle, collected at various physiological stages of its development (early dominant, late dominant and preovulatory stages). Intrafollicular values of sugar chains and $\mathrm{N}$-acetyl groups of glycoconjugates, $\mathrm{CH}_{3}$ groups of lipoproteins, trimethylamines, acetate, alanine, creatine/creatinine and polyamines were related to intrafollicular concentrations of oestradiol and progesterone.

The ${ }^{1} \mathrm{H}$ NMR technique is a unique tool for studying metabolism in intact cells or tissues. It provides an opportunity for obtaining information about a wide variety of organic compounds in various body fluids (Bell et al., 1989; Vion-Dury et al., 1992). This technique has also been used to study serum, as well as bovine and human follicular fluid
(Gosden et al., 1990). However, no data are available in relation to the oestrous cycle of any species.

In the present study, follicular fluids were recovered in vivo by transvaginal puncture of the ovary. Partial aspiration of fluid from the dominant follicle was performed twice during its development. A similar procedure has been carried out in horses and humans (Ahmed-Ebbiary et al., 1995; Gérard and Monget, 1998; Gérard et al., 1998, 1999), and has been shown to allow, for most of the punctured follicles, follicular maturation, ovulation and embryo production. In accordance with previous studies, in the present study it was shown that in follicles the course of which was not affected by puncture, growth was characterized by an increase in oestradiol and progesterone concentrations, whereas maturation after gonadotrophin injection was associated with a decrease in oestradiol and a further increase in progesterone. Other follicles displayed echogenic dots and were characterized by a low intrafollicular content of oestradiol and a high intrafollicular content of progesterone, as described in mares (Gérard and Monget, 1998; Gérard et al., 1998, 1999). It can be assumed that the development failure of some of these follicles was due to the alteration of follicular structure induced by puncture. However, such anovulatory haemorrhagic follicles have already been observed occasionally during the ovulatory season in mares (Ginther, 1979).

In the present study, the intrafollicular content of sugars decreased as the dominant follicle developed to the preovulatory stage, and there was a great decrease after exogenous gonadotrophin injection. This finding is in accordance with that of Gerrard et al. (2000) in which intrafollicular glucose decreased during preovulatory maturation in the mare. Considering that the follicle does not increase in size between the late dominant and the preovulatory stages $(33.8 \pm 0.92 \mathrm{~mm}$ and $31.3 \pm 1.41 \mathrm{~mm}$, respectively), it can be assumed that this intrafollicular depletion of glucose was not due to dilution by water entering the follicle, but could possibly be explained by a lower follicular production. Alternatively, this depletion may result from a local increase in carbohydrate catabolism. This observation has to be related to the metabolic shift that occurs in ovarian glucose utilization at the time of ovulation. This phenomenon, first described by Armstrong and Greep (1962), is mainly characterized by an enhancement of glucose uptake as well as by the diversion of ovarian carbohydrate metabolism away from oxidative phosphorylation towards glycolysis (Harlow et al., 1987; Boland et al., 1993). It is possible that the depletion in intrafollicular glycoconjugates, which occurs in conjunction with the follicle maturation, may be of crucial importance in the normal occurrence of this event or maturation of the oocyte or both. Similar conclusions were obtained with mouse and rat follicles stimulated by gonadotrophins (Nilsson, 1974; Boland et al., 1993).

It is worth noting that very little information is available about intrafollicular polyamine content of any mammal. The ovarian ornithine decarboxylase activity that regulates 
spermine and spermidine synthesis is also poorly understood. In most tissues, these molecules are associated with growth and differentiation (Rosengren et al., 1981). Surprisingly, no change in the intrafollicular polyamine content was observed in the present study. This finding is in accordance with a study performed in rats showing that the intrafollicular spermidine and spermine contents do not change during follicular development and maturation (Sertich et al., 1987). The change in trimethylamine content could be related to polyamine metabolism, as they are also degradation products of cellular metabolism.

In accordance with Le Goff (1994), it was shown in the present study that the concentration of lipoproteins was higher in serum than in follicular fluid. Several studies on follicular fluid lipoproteins are available (Chang et al., 1976; Perret et al., 1985; Brantmeier et al., 1987; Le Goff, 1994). The absence of low density lipoproteins and very low density lipoproteins has been shown in the follicular fluid of women (Perret et al., 1985), sows (Chang et al., 1976), cows (Brantmeier et al., 1987) and mares (Le Goff, 1994). Until the present study, no data were available concerning the variation of lipoproteins during follicular development. In the present study, an increase in the intrafollicular content of lipoproteins $\left(\mathrm{CH}_{3}\right.$ groups) was observed between the late dominant and preovulatory stages. As the intrafollicular concentration of progesterone followed the same profile, it was hypothesized that lipoprotein concentrations are related to the steroidogenic activity of follicular cells. Indeed, high density lipids have been found to activate progesterone synthesis in pig granulosa cells (Rajkumar et al., 1989a,b).

In the present study, two peaks on ${ }^{1} \mathrm{H}$ NMR spectra were observed which were assigned to unidentified products. A similar observation was reported by Magistrini et al. (1995, 2000) in studies on seminal plasma from stallions. However, these peaks were not observed in humans (Vion-Dury et al., 1992), sheep, pigs or cows (Gosden et al., 1990). Thus, it is concluded that these peaks correspond to equine-specific factors.

In conclusion, the results from the present study show clearly that the dynamic process of follicular growth and maturation, as assessed by oestradiol and progesterone content, is associated with specific intrafollicular biochemical changes in mares. The high resolution ${ }^{1} \mathrm{H}$ NMR made it possible to observe: (i) the decrease in lipoproteins and alanine during follicular growth; and (ii) the decrease in glycoconjugates, trimethylamine and acetate, and the increase in lipoproteins during preovulatory follicular maturation. Further experiments are required to determine the involvement of such modifications in cellular differentiation, follicular and oocyte maturation, and further fertilization.

The authors wish to thank staff from the Laboratoire de Dosages Hormonaux (INRA, Nouzilly) for radioimmunoassy of steroids, I. Couty, B. Bruneau and the staff of the experimental study for technical assistance and E. Palmer for his help during statistical analysis. A. Lacombe (Equipe Traduction, INRA, Jouy en Josas) and J. Martin are acknowledged for proof reading and correction of the English. This work was supported by grants from the Institut National de la Recherche Agronomique (INRA, France) and the Haras Nationaux (France).

\section{References}

Adashi EY (1994) Endocrinology of the ovary Human Reproduction 9 Supplement 2 36-51

Ahmed-Ebbiary NA, Lenton EA, Welsby R, Marforth A and Cooke ID (1995) Folliculocentosis: a novel research technique to investigate the intrafollicular endocrine microenvironment Human Reproduction 10 2325-2333

Armstrong DT and Greep RO (1962) Effect of gonadotrophic hormones on glucose metabolism by luteinized rat ovaries Endocrinology $\mathbf{7 0}$ $701-710$

Belin F, Goudet G, Duchamp G and Gérard N (2000) Intrafollicular concentrations of steroids and steroidogenic enzymes in relation to follicular development in the mare Biology of Reproduction 62 1335-1343

Bell JD, Brown JCC and Sadler PJ (1989) NMR studies of body fluids NMR in Biomedicine 2 246-256

Boland NI, Humpherson PG, Leese HJ and Gosden RG (1993) Pattern of lactate production and steroidogenesis during growth and maturation of mouse ovarian follicles in vitro. Biology of Reproduction 48 798-806

Brantmeier SA, Grummer RR and Ax RL (1987) Concentrations of high density lipoproteins vary among follicular sizes in the bovine Journal of Dairy Science 70 2145-2149

Chang SC, Jones JD, Ellefson RD and Ryan RJ (1976) The porcine ovarian follicle. I. Selected chemical analysis of follicular fluid at different developmental stages Biology of Reproduction 15 321-328

Duchamp G, Bour B, Combarnous Y and Palmer E (1987) Alternative solutions to hCG induction of ovulation in the mare Journal of Reproduction and Fertility Supplement 35 221-228

Duchamp G, Bézard J and Palmer E (1995) Oocyte yield and the consequences of puncture of all follicles larger than $8 \mathrm{~mm}$ in mares. In Equine Reproduction VI pp 233-241 Eds DC Sharp and FW Bazer. Society for the Study of Reproduction, Madison

Gérard N and Monget P (1998) Intrafollicular insulin-like growth factorbinding protein levels in equine ovarian follicles during preovulatory maturation and regression Biology of Reproduction 58 1508-1514

Gérard N, Duchamp G, Goudet G, Bézard J, Magistrini M and Palmer E (1998) A high-molecular-weight preovulatory stage-related protein in equine follicular fluid and granulosa cells Biology of Reproduction $\mathbf{5 8}$ $551-557$

Gérard N, Duchamp G and Magistrini M (1999) Relationships between follicular fluid composition and follicular/oocyte quality in the mare Livestock Production Science $60243-253$

Gérard N, Prades A, Couty I, Labberté M, Daels P and Duchamp G (2000) Follicular fluid concentrations of glucose, pyruvate and lactate in relation to follicular growth, preovulatory maturation and oocyte nuclear maturation stage in the mare Theriogenology 53372 (Abstract)

Ginther OJ (1979) Characteristics of the ovulatory season. In Biology of the Mare: Basic and Applied Aspects pp 173-232 2nd Edn. Equiservices, Cross Plains

Gosden RG, Sadler IH, Reed D and Hunter RHF (1990) Characterization of ovarian follicular fluids of sheep, pigs and cows using proton nuclear magnetic resonance spectroscopy Experientia 46 1012-1015

Goudet G, Bézard J, Duchamp G, Gérard N and Palmer E (1997) Equine oocyte competence for nuclear and cytoplasmic in vitro maturation: effect of follicle size and hormonal environment Biology of Reproduction $\mathbf{5 7} 232-245$

Goudet G, Belin F, Bézard J and Gérard N (1998) Maturation-promoting factor (MPF) and mitogen activated protein kinase (MAPK) expression in relation to oocyte competence for in vitro maturation in the mare Molecular Human Reproduction 4 563-570 
Harlow CR, Winston RML, Magara RA and Hillier SG (1987) Gonadotropic control of human granulosa cell glycolysis Human Reproduction 2 649-653

Hinrichs K and Williams KA (1997) Relationships among oocyte-cumulus morphology, follicular atresia, initial chromatin configuration, and oocyte meiotic competence in the horse Biology of Reproduction 57 377-384

Kriat M, Confort-Gouny S, Vion-Dury J, Sciaky M, Viout M and Cozzone PJ (1992) Quantification on components in human blood serum by proton magnetic resonance spectroscopy. A comparative study of the use of formate and TSP as concentration standards NMR in Biomedicine 5 179-184

Le Goff D (1994) Follicular fluid lipoproteins in the mare: evaluation of HDL transfer from plasma to follicular fluid Acta Biochimica et Biophysica Sinica $1210226-232$

Magistrini M, Couty I and Palmer E (1992) Interactions between sperm packaging, gas environment, temperature and diluent on fresh stallion sperm survival Acta Veterinaria Scandinavica Supplementum 88 97-110

Magistrini M, Seguin F, Beau P, Akoka S, Le Pape A and Palmer E (1995) ${ }^{1} \mathrm{H}$ nuclear magnetic resonance analysis of stallion genital tract fluids and seminal plasma: contribution of the accessory sex glands to the ejaculate. In Equine Reproduction VI pp 599-607 Eds DC Sharp and FW Bazer. Society for the Study of Reproduction, Madison

Magistrini M, Lindberg H, Koskinen E, Beau P and Seguin F (2000) Biophysical and ${ }^{1} \mathrm{H}$ magnetic resonance spectroscopy characteristics of fractionated stallion ejaculates Journal of Reproduction and Fertility Supplement $\mathbf{5 6}$ 101-110

Nilsson L (1974) Acute effects of gonadotrophins and prostaglandins on the metabolism of isolated ovarian follicles from PMSG-treated immature rats Acta Endocrinologica 77 540-558

Okolski A, Bézard J, Duchamp G, Driancourt MA, Goudet G and Palmer E (1995) Successive puncture of the dominant follicle followed by ovulation and fertilization: a new model for the study of follicular maturation in the mare. In Equine Reproduction VI pp 385-392 Eds DC Sharp and FW Bazer. Society for the Study of Reproduction, Madison

Palmer E, Bézard J, Magistrini M and Duchamp G (1991) In vitro fertilisation in the horse, a retrospective study Journal of Reproduction and Fertility Supplement 44 375-384
Payer AF (1975) Permeability of ovarian follicles and capillaries in mice American Journal of Anatomy 142 295-318

Perret BP, Parinaud J, Ribbes H, Moatti JP, Pontonnier G, Chap H and Douste-Blazy L (1985) Lipoprotein and phospholipid distribution in human follicular fluids Fertility and Sterility $\mathbf{4 3}$ 405-409

Rajkumar K, Ly H, Schott PW and Murphy BD (1989a) Use of low-density and high-density lipoproteins in undifferentiated porcine granulosa cells Biology of Reproduction 41 855-861

Rajkumar K, Ly H, Schott PW, Njaa B and Murphy BD (1989b) Evidence for differences in low density lipoprotein processing by porcine granulosa and luteal cells in vitro: effect of addition of serum for plating of granulosa cells on lipoprotein metabolism Journal of Endocrinology 122 557-564

Rosengren E, Henningsson AC, Henningsson E and Persson L (1981) Polyamine metabolism as related to growth and hormones Medical Biology 59 320-326

Seguin F, Magistrini M, Beau P, Palmer E and Lepape A (1995) Preliminary analysis of equine seminal plasma by ${ }^{1} \mathrm{H}$ NMR Journal of Magnetic Resonance Analysis 1 53-57

Sertich GJ, Perrson L and Pegg AE (1987) Regulation of ovarian ornithine decarboxylase by human chorionic gonadotrophin American Journal of Physiology 253 687-692

Tsafriri A (1988) Local nonsteroidal regulators of ovarian function. In The Physiology of Reproduction pp 527-565 Eds E Knobil and JD Neill. Raven Press, New York

Van den Thillart G and Van Waarde A (1996) Nuclear magnetic resonance spectroscopy of living systems: applications in comparative physiology Physiological Reviews 76 799-837

Vion-Dury J, Nicoli F, Torri G et al. (1992) High resolution NMR spectroscopy of physiological fluids: from metabolism to physiology Biochimie 74 801-807

Received 19 December 2001.

First decision 7 March 2002.

Final manuscript received 23 April 2002.

Accepted 8 May 2002. 